\title{
A INVISIBILIDADE DA IMAGEM NA PROSA FINAL DE BECKETT
}

\author{
Annita Costa Malufe
}

Universidade de São Paulo

\section{Resumo}

A prosa final de Samuel Beckett parece ter sido pautada por um desejo de esvaecimento de todas as imagens. Sua literatura da "despalavra" (non mot) é marcada por personagens e cenários insólitos, surgindo na fronteira de sua própria dissolução. Imagens frágeis, fugidias, que colocam em xeque o jogo da percepção comum, deslocando tempo e espaço. Que imagens são essas, que dão corpo a uma espécie de invisibilidade ou limite da visão? O vazio ou o nada: como figurá-los? Como dar corpo ao que escapa, ao que não tem forma perceptível? Essas questões são as que nos conduzem a pensar acerca da imagem, tal como presente-ausente na literatura de Beckett, e seus desdobramentos para a leitura do texto beckettiano.

\section{Abstract}

The Samuel Beckett's final prose seems to have been guided towards an evanescence of all images. His "non mot" literature is marked by an unusual characters and scenarios, emerging on the border of its own dissolution. We have fragile images that challenge the common perception, shifting time and space. Which is the statute of these images that embody a kind of invisibility or limit of the vision? The emptiness or nothingness: how to figure them? How can we embody non-perceptive forms? These are the questions that lead us to think about the image as present-absent in Beckett's literature and its consequences for the reading of Beckett's text. 
Pintar uma imagem em vias de desaparecer. Tal projeto - inviável, impossível - é o que parece ter pautado a prosa final de Samuel Beckett. Personagens e cenários insólitos, tomados por um processo de rarefação, esvaecimento, como se já surgissem na fronteira de sua própria extinção. Que imagens são essas, que dão corpo a uma espécie de invisibilidade, de visão no limite do figurável? Algo neste tipo de imagem, que mais e mais surge nos textos de Beckett, talvez cumpra o que ele diz a respeito dos pintores Abraham e Gerardus van Velde, mas que, quem sabe, se refira a um programa próprio: "Forçar a invisibilidade inata das coisas exteriores até que esta invisibilidade ela mesma se torne coisa, não simples consciência de limite, mas uma coisa que podemos ver e fazer ver (...)". ${ }^{1}$

O vazio ou o nada: como figurá-los? Como dar corpo ao que escapa, ao que não tem forma perceptível? Problema abordado de modo semelhante pelo pintor Paul Klee, para quem a arte não reproduz o visível mas antes "torna visível", ou seja, nos faz ver o que antes seria da ordem do invisível ${ }^{2}$. O tempo ou o movimento, por exemplo, ou o próprio som e, com ele, o silêncio. Como pintar ou dizer o silêncio? Quando se trata da literatura de Beckett, a questão assim colocada nos ajuda a pensar na natureza dessa imagem que se dá em uma escrita que busca fugir da modalidade meramente figurativa ou representativa da linguagem. Afinal, como podemos falar em imagens em uma escrita que se debate para se livrar tanto da faceta realista quanto retórica (no sentido da retórica clássica)? Seria possível criar, também na literatura, uma imagem anti-figurativa, como o parece ser na pintura?

Sabemos que esta libertação (da retórica e da mimeses) é uma tarefa a que Beckett encarregava não somente a sua, mas toda a literatura de seu tempo. Seria urgente liberar a escrita do que seria "o velho estilo", como repete a personagem Winnie na peça Dias felizes. Seria preciso se livrar do "inglês oficial", mais e mais um fardo para Beckett, como lemos em sua conhecida carta alemã, de 1937. A gramática e o estilo aí colocados como máscaras obsoletas e artificiais e sua própria língua como um véu a ser rasgado para que fosse possível se chegar às coisas (ou ao Nada), escondidos por detrás das palavras. É aqui que ele se refere diretamente à tarefa, dada ao escritor, de conduzir mal a língua, levá-la à desgraça ${ }^{3}$. Como em Worstward Ho (Pra frente o pior, na recente tradução brasileira de Ana Helena Souza): "Dizer por ser dito. Dito mal. Desde agora dizer por ser dito mal"4. Mote reiterado ao longo de toda sua obra final. A língua seria mais bem usada quanto mais próxima de seu próprio fracasso. Talvez aí Beckett explicite o que ele dizia ser a impossibilidade da expressão, em Trois

\footnotetext{
${ }^{1}$ Samuel Beckett, Le Monde et le pantalon, Paris, Minuit, 1989, p. 41.

2 "L'art ne donne pas une reproduction du visible, mais il rend visible." Paul Klee, "Confession créatrice" (conferência publicada pela primeira vez em 1920). In: La Pensée créatrice, Paris, Dessain et Tolra, 1980 , p. 76. ${ }^{3}$ Reproduzo o trecho conhecido desta carta, na tradução de Fábio de Souza Andrade: "Está se tornando mais e mais difícil, até sem sentido, para mim, escrever num inglês oficial. E, mais e mais, minha própria língua me parece como um véu que precisa ser rasgado para chegar às coisas (ou ao Nada) por trás dele. Gramática e Estilo. Para mim, eles parecem ter se tornado tão irrelevantes quanto o traje de banho vitoriano ou a imperturbabilidade do verdadeiro cavalheiro. Uma máscara. Tomara que chegue o tempo, graças a Deus que em certas rodas já chegou, em que a linguagem é mais eficientemente empregada quando mal empregada. Como não podemos eliminar a linguagem de uma vez por todas, devemos pelo menos não deixar por fazer nada que possa contribuir para sua desgraça. Cavar nela um buraco atrás do outro, até que aquilo que está a espreita por trás - seja isto alguma coisa ou nada - comesse a atravessar; não consigo imaginar um objeto mais elevado para um escritor hoje." Beckett, "Carta alemã de 1937”. In: Fábio de Souza Andrade. Samuel Beckett: o silêncio possível. São Paulo: Ateliê, 2001.

${ }^{4}$ Samuel Beckett. "Pra frente o pior". In: Companhia e outros textos. Trad. Ana Helena Souza. São Paulo: Globo, 2012, p. 65.
} 
dialogues,${ }^{5}$ ou da representação do objeto, em Le Monde et le pantalon, ${ }^{6}$ não restando à arte senão a alternativa de se engajar na dramatização deste inevitável desvio da representação.

Como fazer com que as palavras representem a impossibilidade de representar? De algum modo, Beckett responde a isto sobretudo a partir do processo que se desencadeia em seu estilo na trilogia da década de $1950^{7}$, buscando paulatinamente a ineficiência da função designativa e significativa da linguagem. "É preciso continuar, não posso continuar, vou continuar": os últimos segmentos de O inominável parecem repetir-se infindavelmente nas obras beckettianas que se seguem à trilogia, marcando o impasse em que o próprio Beckett se viu após a conclusão deste terceiro volume: "Comment continuer après l'INNommable? (sic.)", pergunta-se ele ${ }^{8}$.

Para seguir, será preciso intensificar, a partir do romance enfim publicado em 1961, Como é ${ }^{9}$, as estratégias para efetivamente criar o que ele chama de uma literatura do non-mot, da despalavra. Esforço por uma linguagem que a todo tempo coloca em cena o confronto entre significar e des-significar, dizer e não dizer, lembrar e esquecer, a memória e a falha da memória. A linguagem que dramatizará sem cessar uma briga consigo mesma. O significado que quase não se faz, a imagem que quase não se completa ou, ao se fazer, logo se pulveriza. Mais e mais as visões são falhas, borradas. A linguagem embaça as imagens, fazendo-nos ver mal, enxergar a duras penas o que se delineia adiante da narrativa. São imagens “(...) precárias, instáveis e suscetíveis de dissolução", para nos valermos da definição de André Bernold ${ }^{10}$. Assim, dizer mal é cada vez mais nos fazer ver e conceber mal o suposto real, como acontece exemplarmente, não somente no título, em Mal visto mal dito. E como se dá de modo culminante nos três títulos desta que seria a sua segunda trilogia, em especial na última obra, Pra frente o pior ${ }^{11}$.

Esta ideia da mal condução da linguagem é tão importante que é praticamente obrigatório que os autores que se debruçam sobre o estilo tardio de Beckett passem pelas suas estratégias de "dizer mal", ou de fazer a linguagem fracassar ao tentar dizer as coisas. Então, ao invés do que seria mais comum - o estudo dos modos de se "dizer bem", ou dizer melhor alguma coisa -, em Beckett, é preciso buscar os procedimentos criados para deixar de dizer, para não dizer, ou dizer mal. E nos fazer, consequentemente, "ver mal" através das palavras: "Ver por ser visto. Visto mal. Desde agora ver por ser visto mal"12.

É assim que a pesquisa acerca do estilo de Beckett acaba enveredando pelos procedimentos que se intensificam em sua obra no sentido de fazer a linguagem falhar em sua função de significação e designação; e mesmo de manifestação de um sujeito, como tanto se

\footnotetext{
${ }^{5}$ Samuel Beckett. Trois dialogues. Paris: Minuit, 1998, p. 14.

${ }^{6}$ Samuel Beckett. Le Monde et le pantalon, op. cit., p. 56.

${ }^{7}$ Molloy, 1951; Malone meurt, 1951; L'Innommable, 1953.

8 "Como continuar depois de O inominável?". Carta a Mania Peron, de 16 de abril de 1951. (A redação de $O$ inominável data de 1949 e sua primeira publicação é de 1953.) Diversas cartas de Beckett referem-se ao impasse criativo que ele teria chegado após esse romance. Ver: Samuel Beckett. The Letters of Samuel Beckett v. II (19411956). Ed. George Craig, Martha Dow Fehsenfeld and Lois More Overbeck. Cambridge: Cambridge University Press, 2011, p. 240.

${ }^{9}$ Samuel Beckett. Comment c'est. Paris: Minuit, 1961.

${ }^{10}$ André Bernold. L'Amitié de Beckett. Paris: Hermann, 1992, p. 59.

11 Tida por alguns como a trilogia da década de 80, composta por: Company/Compagnie, 1980; Mal vu mal dit/Ill seen Ill said, 1981; e Worstward Ho, 1983 - escrita em inglês e traduzida por Edith Fournier por Cap au pire - o próprio Beckett não o fez por considerar esse texto intraduzível.

12 Samuel Beckett. "Pra frente o pior", op. cit., p. 68.
} 
apontará em relação a Beckett. Falhar em representar, em figurar. São efeitos conquistados na escrita a partir de estratégias de construção de linguagem, ou estratégias que, para alguns, como Bruno Clément, não deixam de ser um trabalho de retórica - ainda que tenham como objetivo desfazer a retórica clássica, e buscar justamente tais efeitos de inacabamento, instabilidade, informalidade, precariedade ${ }^{13}$. O que importa é que se trata de um extremo rigor construtivo, sobre a forma, para que o efeito de informalidade, e de improviso, como destaca Clément, de fato consiga se dar. Estratégias de "desfiguração", como diz Evelyne Grossman; de "indeterminação" e ausência, segundo Marjorie Perloff; de "abstração", para Pascale Casanova; dispositivos de interferência ou rasura generalizada da imagem, em Isabelle Ost. Ou, ainda, no caso de Gilles Deleuze, estratégias de "esgotamento do possível", que têm como ponto culminante, justamente, a construção daquilo que o filósofo chamará de imagem em um sentido específico do termo, como veremos adiante.

As estratégias para falhar são também aquelas de "fazer buracos" na superfície aderente da língua, como diz Beckett na carta citada: "Cavar nela [na linguagem] um buraco atrás do outro."14 Há algo que se esconde por detrás da linguagem. Como se ela fosse codificada demais, carregada de memória, historicizada, e portanto fechada demais, para nos deixar vazios, em que coisas inesperadas possam irromper. É inevitável que as palavras digam, que elas representem. É contudo inevitável que elas, ao representarem, limitem nosso campo de visão e nossas possibilidades de vislumbrar algo para além do mundo concreto, rebatido e cotidiano, tomado de sensos comuns, de conexões já viciadas. É difícil portanto que as palavras se libertem do clichê da representação, dos reflexos já existentes do mundo; difícil que elas criem por si novas imagens, dando-nos visões e sons inéditos, ou mesmo um pouco de vácuo, vazio. As palavras "colam", e não nos deixam experimentar aquilo que Beckett chamou de "abismos insondáveis de silêncio" - aos quais a música por exemplo conseguiria nos fazer ouvir. Daí a extrema necessidade em romper a superfície aderente da língua, a que ele alude em sua carta, dizer respeito a como fazer com que algo possa ser visto ou ouvido por detrás delas, algo talvez inominável, algo talvez inédito. Algo, como dirá Deleuze, livre das aderências que manteriam as palavras ou no geral - no campo dos conceitos gerais, genéricos do senso comum -, ou no particular, que é o campo da experiência subjetiva, privada.

Seria preciso se livrar dessas aderências para que as palavras encontrem um ponto em que elas, tornadas independentes, sejam capazes de produzir "visões e sons que permaneciam imperceptíveis por trás da velha linguagem", diz Deleuze referindo-se às ideias de Beckett ${ }^{15}$. Perfurar para que elas se livrem tanto do sujeito que fala, quanto do objeto de que se fala, liberando então aquilo que Deleuze chamará de imagem. Alguma coisa neste tipo de imagem dirá portanto respeito a uma imagem que se desprega de sujeitos e objetos, como se ganhasse uma existência autônoma. Ela é, de fato, algo que se autonomiza, que salta das palavras, como que tornada independente delas. Cores, sons, ritmos tornados autônomos, como se virassem seres com uma espécie de vida própria, uma vida concreta e real, porém, de uma natureza incorporal, natureza das forças.

13 Bruno Clément. L'œuvre sans qualités - rhétorique de Samuel Beckett. Paris: Seuil, 1994, p. 195. ${ }^{14} \mathrm{Na}$ tradução francesa: "Y forer un trou après l'autre". In: Samuel Beckett, Objet Beckett. Paris: Éditions du Centre Pompidou/ Imec, 2007, p. 15.

15 Gilles Deleuze, “L’Épuisé”. In: Samuel Beckett, Quad et autres pièces pour la télévision. Paris: Minuit, 1992, p. 105. 
É interessante destacar que em seu livro Crítica e clínica, composto de ensaios diversos ocupando-se da literatura, Deleuze convoca Beckett logo no início, justamente para se referir à ideia, cara a ele, de que haveria uma música e uma pintura próprias às palavras, cores e sonoridades que seriam como que efeitos disparados pelas palavras. Ou seja, as palavras não simplesmente representando algo, uma cena, um som, mas servindo como disparadores de imagens (sonoras, visuais) que são reais (embora incorporais); imagens da natureza de um efeito que acontece no leitor no embate com o texto:

O limite não está fora da linguagem, ele é o seu fora: é feito de visões e audições não-
linguageiras, mas que só a linguagem torna possíveis. Por isso há uma pintura e uma
música próprias da escrita, como efeitos de cores e sonoridades que se elevam acima
das palavras. É através das palavras, entre as palavras, que se vê e se ouve. Beckett
falava em 'perfurar buracos' na linguagem para ver e ouvir 'o que está escondido
atrás'. De cada escritor é preciso dizer: é um vidente, um ouvidor, 'mal visto mal
dito', é um colorista, um músico. ${ }^{16}$

Cada escritor conseguiria portanto provocar, à sua maneira, essas visões ou audições grandiosas, inesperadas, inéditas. Cores, sons, texturas, velocidades; imagens que aparecem no meio das palavras quando elas de algum modo conseguem dar a sentir (ver, ouvir) algo que extrapola a faceta representacional, linguística, da própria língua. Assim, essas visões e sons escondidos por detrás do velho estilo seriam imagens que se dão no limite da linguagem, ali onde a linguagem raspa em suas próprias bordas. É quando a língua falha e algo não se completa, não se dá, que a própria língua esbarra em seu limite - seu próprio limite de palavra, de significante-significado, sua natureza de signo que significa, designa, manifesta. Limite assintático, agramatical. Ao falhar, a linguagem é perfurada e virada do avesso - Deleuze dirá que é "como se as palavras agora regurgitassem seu conteúdo"17, fazendo vasar imagens-sons, imagens-visões. E neste instante é como se a linguagem tocasse o ponto em que palavras e corpo coexistem de modo indiscernível. Daí ela tocar seu próprio limite.

No estilo tardio de Beckett, segundo Evelyne Grossman, a tal perfuração da superfície da língua (cavar buracos ou forer des trous) consistiria em desfazer as articulações sintáticas da linguagem comum ${ }^{18}$. Os procedimentos são diversos neste sentido de uma "desfiguração", como diz Grossman, que passa sobretudo por desfigurar a própria sintaxe: reiteração e permutação de palavras, orações incompletas, reticentes, subtração do objeto designado ou do sujeito manifestante, ou ambos, rupturas dos mais diversos tipos, etc. Em Pra frente o pior, por exemplo, temos esses procedimentos sintáticos levados a uma exacerbação.

Primeiro o corpo. Não. Primeiro o lugar. Não. Primeiro os dois. Ora um. Ora o outro. Farto do um tentar o outro. Farto deste de volta farto do um. Assim por diante. De algum modo adiante. Até farto dos dois. Vomitar e ir. Onde nenhum. Até farto de lá. Vomitar e de volta. O corpo de novo. Onde nenhum. O lugar de novo. Onde nenhum. Tentar de novo. Falhar de novo. Melhor de novo. Ou melhor pior. Falhar pior de novo. Ainda pior de novo. Até farto de vez. Vomitar de vez. Ir de vez. Onde nenhum deles de vez. De uma vez por todas. ${ }^{19}$

\footnotetext{
${ }^{16}$ Gilles Deleuze. Crítica e clínica. trad. Peter Pál Pelbart. São Paulo: Ed.34, 1997, p. 9.

17 "É uma pintura ou uma música, mas uma música de palavras, uma pintura com palavras, um silêncio nas palavras, como se as palavras agora regurgitassem seu conteúdo, visão grandiosa ou audição sublime." Idem, p. 128.

${ }^{18}$ Evelyne Grossman. La Défiguration - Artaud-Beckett-Michaux. Paris: Minuit, 2004, p.70-71.

${ }^{19}$ Samuel Beckett, "Pra frente o pior", op. cit., p.65-66.
} 
Como neste bloco, o texto é todo pontuado por inúmeras palavras ou expressões que retornam como motes. Muitas orações são truncadas, invertidas e, não raro, encontramos frases compostas por mais de um segmento que, no entanto, não são separados por pontuação alguma (por exemplo: "Onde nenhum"; "Onde nenhum deles de vez", no caso deste fragmento). Todos esses procedimentos desarticuladores da sintaxe têm como efeito provocar a desestabilização da função de significar, tornando as palavras "frágeis" e criadoras de enigmas, como diz Marjorie Perloff ${ }^{20}$. Uma vez que a camada semântica é erodida, predomina nesses textos uma certa atmosfera nebulosa, em que paira algo de mistério ou de difícil visibilidade e compreensibilidade. São estratégias de escrita que provocam uma erosão naquilo que seria a memória da palavra, suas aderências, seus clichês. E pode ser que essa desarticulação sintática seja realizada de modo que, diz Perloff, muitas vezes, sejamos conduzidos pelas frases sem nos darmos conta de que a ordem sintática é apenas uma ilusão, que ela esconde gaps que estão sutilmente infiltrados entre as orações, corroendo-as por dentro.

Lembremo-nos que a proposta de Deleuze, no ensaio "L'Épuisé", é a de que haveria três línguas em Beckett. A língua 1, língua dos nomes (que prevaleceria nos primeiros romances), dos objetos; língua 2, língua das vozes, dos fluxos de vozes (marcante na trilogia da década de 50, em especial O inominável) e a língua 3, esta língua das imagens, que explodiria a partir de Comment c'est marcando a prosa que se segue e as peças para televisão (ele destaca a trilogia final e, poderíamos acrescentar, os textos breves das décadas de 60 e 70, dos quais Bing e Sans seriam exemplares). De algum modo, essas três línguas coexistiriam nas obras finais de Beckett, sendo que a língua 3, a das imagens, tem como papel de algum modo desfazer as outras duas. Ela surge como um terceiro modo de esgotamento das possibilidades da língua; um modo que rompe a relação língua-objeto (língua 1) e a relação língua-voz ou língua-sujeito de enunciado (língua 2). Um modo que rompe com a memória, com imagens que, na língua 2 , a das vozes, estariam às vezes ainda coladas ao sujeito ou ao objeto designado, ainda colando a voz às lembranças pessoais - são as "imagens-lembrança", images-souvenirs, dirá ele ${ }^{21}$. Daí o tema tão recorrente da memória, sempre sob o signo do esquecimento e do lapso, na obra de Beckett. Corpos que se fazem na rearticulação desordenada de fragmentos da memória, que reinventam um outro tempo, não mais preso à rememoração de um sujeito - fato que se intensifica na prosa final ${ }^{22}$.

Será, assim, nesses gaps, que rompem o fluxo das vozes, inserem lapsos que fragmentam e desarticulam as imagens-lembrança, que poderá surgir uma imagem "pura", uma imagem autônoma, que surge como irrupção de algo novo, singular. Ela será o que se faz, de tempos em

\footnotetext{
${ }^{20}$ Marjorie Perloff. The poetics of indeterminacy - Rimbaud to Cage. Evanston: Northwestern University Press, 1999 , p. 200.

${ }^{21}$ Gilles Deleuze, “L'Épuisé”, op. cit., em especial na nota da p. 70, referência de que em Companhia algumas imagens não conseguiriam chegar ao ponto de se autonomizar de algumas imagens-lembrança. ${ }^{22}$ Embora, para Deleuze, a obra para televisão ocupe aqui um lugar central, sendo onde Beckett teria encontrado a realização mais exemplar desse tipo de imagem. Vale salientar que o conceito de imagem trabalhado neste ensaio por Deleuze remete a seu estudo sobre cinema, em especial Cinema 2 - a imagem-tempo, em que ele falará de uma mudança trazida pelo neorrealismo italiano e a Nouvelle Vague no sentido de produzir situações óticas e sonoras puras, já numa crise da ação e da representação do cinema. As descrições aí já não virão em função de representar uma cena, mas ganharão uma existência por si só. A imagem "pura" portanto será a autonomização de cores e sons - e do próprio tempo - que passam a valer por si. Cf. Gilles Deleuze Cinema 2 - l'image-temps, Paris, Minuit, 1985.
} 
tempos, quando a superfície figurativa consegue ser efetivamente rompida, liberando algo de cor ou de som por entre as palavras, conforme a proposta presente na carta alemã de Beckett já vista: "Cavar nela um buraco atrás do outro, até que aquilo que está a espreita por trás - seja isto alguma coisa ou nada - comesse a atravessar", ou algo comece a vasar, "suinter", se seguirmos a tradução francesa desta mesma carta. Por isto a imagem surgirá no corte; ela será aquilo que salta nos hiatos, nos lapsos ou brancos que são criados por Beckett com os procedimentos de linguagem: "Hiatus pour lorsque les mots disparus", conforme o trecho de Pra frente o pior, citado por Deleuze na tradução francesa, Cap au pire ${ }^{23}$, que na tradução brasileira lemos: "Brancos para quando as palavras se forem" 24 . A imagem salta nesses buracos na superfície, nesses furos que viriam a partir da desarticulação sintática, das inúmeras formas encontradas para "dizer mal" e torcer as palavras. Formas que se encaminham para essa língua atomizada, na última fase, que se faz a partir de um fluxo todo entrecortado, repleto de falhas, rupturas, torções e reiterações.

Os vazios donde saltam as imagens são assim inseridos nas valas entre uma oração e outra - o que pode vir por exemplo nas descrições de lugares impossíveis e jamais visualizáveis pela visão comum, como aponta Perloff. Em modos de descrever e narrar que incluem caminhos, visões ou mesmo movimentos do corpo contraditórios. Perloff chama a atenção para o fato de que, se tentarmos descrever as paisagens ou lugares beckettianos, rapidamente descobrimos a impossibilidade de visualizá-los ou concebê-los de modo nítido - e aqui ela se debruça sobre textos curtos da década de 70 (Foirades/ Fizzles), para ela característicos do seu estilo tardio. Vejamos o trecho inicial citado por ela, na versão em inglês:

Closed place. All needed to be known for say is known. There is nothing but what is
said. Beyond what is said there is nothing. What goes on in the arena is not said. Did
it need to be known it would be. No interest. Not for imagining. Place consisting of an
arena and a ditch. Between the two skirting the latter a track. Closed place. Beyond
the ditch there is nothing. This is known because it needs to be said. Arena black vast.
Room for millions. ${ }^{25}$

Beckett, neste caso, provoca um choque nas suas descrições, criando lugares impossíveis, em imagens que parecem se contradizer: por um lado "lugar fechado" e depois "lugar consistindo em arena e valeta", em seguida "atrás da valeta não há nada", mas por outro dirá depois "torres de luz pálida". Ficamos entre saber se a arena seria um anfiteatro em um lugar aberto ou seria este "lugar fechado", atrás do qual não há nada, lugar fechado da linguagem, que é citado no início, se é um lugar para muitos ou para ninguém. Perloff mostra diversas dessas disjunções que compõem as supostas descrições de lugares em Beckett; uma das estratégias para criar lugares de difícil visualização, em que um mesmo cenário pode se compor de imagens múltiplas e até mesmo contraditórias. Criando o que Deleuze chama de "lugares quaisquer" tanto nas peças como na prosa de Beckett, quanto no cinema da Nouvelle Vague. Nem referências espaciais, nem contexto temporal preciso, temos frequentemente a criação de um "espaço-tempo flutuante", ${ }^{26}$ diz Isabelle Ost, criados às vezes a partir de

\footnotetext{
${ }^{23}$ Samuel Beckett, Cap au pire, trad. Edith Fournier, Paris, Minuit, 1991, p. 53.

${ }^{24}$ Samuel Beckett, "Pra frente o pior", op. cit., p. 84.

25 Trecho de "Frizzle 5" de Beckett, in: Marjorie Perloff, The Poetics of Indeterminacy, op. cit., p. 201.

${ }^{26}$ Isabelle Ost, op. cit., p. 268. Os falsos raccords são apontados por Deleuze no capítulo "Les puissances du faux", de Cinema 2 - l'image-temps, referência também para Ost.
} 
procedimentos cinematográficos, de um tipo singular de montagem - Ost chamará Mal visto mal dito de um "texto-filme", construído a partir de cortes e falsos raccords ${ }^{27}$.

Isto apenas para pensarmos em alguns modos frequentes de desarticulação entre palavras e coisas que encontramos em Beckett e que faz com que a dimensão designativa da linguagem seja abalada, criando imagens menos passíveis de serem fixadas pela percepção. Há vazios entre as orações, gaps, descontinuidades que desarticulam a figuração espaço-temporal. Espaço e tempo são desarticulados e, com eles, sujeito e objeto. A imagem, neste caso, é aquilo que irrompe e provoca o que José Gil, ao se referir à poética de Fernando Pessoa, chama de uma "desarticulação do espaço perceptivo comum" ${ }^{28}$, como se desarticulasse o plano da percepção e nos fizesse por isto ganhar novas percepções, novos modos de perceber. Daí a imagem não ser da ordem da percepção, mas sim daquilo que Deleuze define como sensação. Ela é aquilo que justamente opera uma mudança na nossa percepção comum, um salto que a desestabiliza.

Daí esse tipo de imagem se definir por certa evanescência, ela é frágil e efêmera, ela possui uma potência dissipativa. Ela é, para Deleuze, um sopro, "em vias de extinção"29. Diferentemente do que propõe por exemplo Martin Esslin em seu texto "Une poésie d'images mouvantes", a imagem de que fala Deleuze, e que nos interessa aqui, não é aquilo que se fixa e que sintetizaria, como um emblema ou um símbolo, como algo de central ou essencial do texto. Para Esslin, o teatro de Beckett seria marcado pelo uso de imagens visuais fortes, que para ele são metáforas, que teriam o poder de sintetizar cada uma das peças, criando um tableau (a boca em Not I, as três cabeças em Play, as figuras de Quad, a dupla de Godot, enquanto imagem da imobilidade etc.). Já para Deleuze não é o teor metafórico que definiria a imagem singular criada na literatura de Beckett. Ao contrário, interessa-lhe esse tipo de imagem não-figurativa, que de algum modo conseguiria escapar das figuras de linguagem e criar o almejado "furo" na superfície da língua.

Daí interessarem-lhe em Beckett essas imagens frágeis, que surgem em vias de sua própria dissolução, tendo como característica não durar muito tempo. "Elas se confundem com a detonação, a combustão, a dissipação de sua energia condensada", diz Deleuze ${ }^{30}$. E tal ideia me parece bastante adequada para pensarmos nessas imagens difíceis de serem apanhadas, nesses flashes que parecem compor as últimas obras, essas imagens borradas, cheias de interferências, como diz Isabelle Ost. A criança e o velho homem, em seguida a velha mulher, curvados, que surgem em flashes e logo somem, em Pra frente o pior. Há algo de espectral nessas imagens, como a da mulher que assiste ao levantar de Vênus, de sua cabana, "no inexistente centro de um espaço sem forma", em Mal visto mal dito ${ }^{31}$. O ir e vir desta mulher que parece surgir e desaparecer numa paisagem inexistente, que se mistura com o céu, o horizonte, as pedrinhas, a aurora ou a janela: "Longamente esta imagem até que bruscamente ela se borra" 32 .

\footnotetext{
${ }^{27}$ Idem, p. 270.

28 José Gil, Fernando Pessoa ou a metafísica das sensações, Lisboa, Relógio D’Água, 1996, p. 26.

${ }^{29}$ Gilles Deleuze, "L'Épuisé", op. cit., p. 97.

${ }^{30}$ Idem, p. 76.

31 "Le cabanon. À l'inexistant centre d'un espace sans forme." Samuel Beckett, Mal vu mal dit, Paris, Minuit, 1981, p. 9.

32 "Longuement cette image jusqu'à ce que brusquement elle se brouille." Idem, p. 22.
} 
Tais imagens parecem ser da natureza do que narra Beckett, mais uma vez acerca dos pintores Van Velde: “Aqui tudo se move, nada, foge, retorna, se desfaz, se refaz. Tudo cessa, sem cessar. Diríamos a insurreição das moléculas, o interior de uma pedra um milésimo de segundo antes que ela se desagregue. É isto a literatura." 33 São imagens prestes a se desagregar, a explodir e se dissipar, como se elas surgissem cavando um buraco no meio do embaralhamento das palavras e logo fossem de novo engolidas por essa massa de palavras, como que submersas pela linguagem: "antes que o olho tenha tempo eis que a imagem embaça." ${ }^{34}$ Elas são frágeis, daí elas terem quase sempre um conteúdo muito simples. Deleuze dirá que não é o conteúdo, muitas vezes pobre, que a define, mas sim a sua força para romper o tecido da língua. Assim, essa imagem não é nem mesmo um objeto, mas um "processo"35. Ela se define justamente pela força que mobiliza para criar esse vazio, esse silêncio ou esses buracos, que são também buracos na memória e na razão: "pequena imagem alógica, amnésica, quase afásica." 36

De modo que ela não precisa ser necessariamente uma imagem visual; ela também pode ser sonora, verbal, textural. Ela pode ser, por exemplo, um som que se repete pontuando o fluxo da linguagem - "bing" ou "hop" (no breve texto Bing) ou Pim (em Como é). No caso de Bing, como diz Renée Riese Hubert, esses sons produzem uma parada ou ruptura na continuidade da frase. Jamais avizinhados no texto, "bing" e "hop" surgem em novas combinações, permutam-se e ambos parecem inserir os hiatos no texto: "bing" ligando-se ao silêncio e "hop" à imobilidade ${ }^{37}$. No caso de Como é o próprio nome do personagem a que o narrador se refere serve de nota musical reiterada e a estrutura em blocos de tamanhos variáveis separados por brancos possui por si uma imagem, tanto sonora quanto visual. A imagem pode ainda surgir de uma repetição que sobressai e se autonomiza, criando uma imagem verbal que nos sugere uma música muito singular, vinda por exemplo da permutação e retorno irregular de expressões ou palavras, como acontece exemplarmente também nesses textos, ou em Sans e em muitos momentos de Mal visto mal dito ou Pra frente o pior. Frases inteiras que se repetem, de modo irregular e são permutadas em seus elementos, retornando com pequenas variações e criando novas associações entre si. Exemplar a este respeito é o

${ }^{33}$ Samuel Beckett, Le Monde et le pantalon, op. cit., p. 35.

34 “(...) avant que l'œil en ait le temps voilà que l'image s'embue." Samuel Beckett, Mal vu mal dit, op. cit., p. 40 .

35 Gilles Deleuze, "L’Épuisé", op. cit., p. 72. Neste ponto, vale apontar que Didi-Huberman, em seu ensaio "Image" (incluído em Objet Beckett), demonstra certa incompreensão acerca do conceito de "imagem pura" proposto por Deleuze, uma vez que a imagem pura nada tem a ver com o objeto puro da fenomenologia. Muito ao contrário, Deleuze busca com isto nomear algo que não é da ordem da percepção, mas sim da ordem das forças ou do que ele chamará de intensidade. Para os propósitos deste artigo, não precisamos entrar no teor filosófico do debate, cabendo-nos apenas extrair do conceito de Deleuze a relevância de uma imagem cuja natureza se não se restringe ao dado empírico, material, atual, e que, justamente por isto, também não cairia no polo transcendente, suprarreal (imaginário versus real). A imagem, neste caso, é tão real quanto os corpos de carne e osso, a questão é somente ela ser de uma outra natureza (o "pura" referindo-se à pura natureza intensiva, virtual), cf. Gilles Deleuze, Cinema 2 - l'image-temps, op. cit., e acerca da questão atual e virtual ver ainda: Gilles Deleuze e Claire Parnet, "L'Actuel et le virtuel", in: Dialogues, Paris, Champs, 1996, p.179-185.

36 Idem, ibidem.

${ }^{37} \mathrm{O}$ autor salienta a busca do leitor de Bing por traços de qualquer coisa de concreto neste que, para ele, seria um dos textos beckettianos mais difíceis de se encontrar pontos de referência e se localizar. Renée Riese Hubert, "À la trace de Bing”, in: Cahier de l'Herne, Samuel Beckett. Édition de 1'Herne, 1976, p. 269-279. 
último poema de Beckett, "Comment dire"38, em sua estrutura que vai crescendo paulatinamente com o acréscimo de novas palavras que vêm juntar-se às anteriores:

\section{COMMENT DIRE}

folie -

folie que de-

que de-

comment dire -

folie que de ce-

depuis -

folie depuis ce-

donné -

folie donné ce que de-

$v u-$

folie vu ce-

ce-

comment dire -

ceci-

ce ceci-

ceci-ci-

tout ce ceci-ci-

folie donné tout ce-

$v u-$

folie vu tout ce ceci-ci que de-

que de-

comment dire - (...)

Veríamos surgir aí uma "imagem verbal, como em um Lied", diz Deleuze, ou ainda: "a música e a cor como em um poema". Som que se liga à visualidade, visão que emerge de combinações verbais. Ou seja, a imagem assim pensada necessariamente implicará em um cruzamento dos sentidos, uma vez que ela não é da ordem da percepção mas é, antes, da ordem das forças, e as forças são em si mesmas imperceptíveis: só podemos perceber o efeito das forças sobre as coisas extensas, dirá Deleuze. Afinal, como teríamos cores em um poema? E de que natureza é uma imagem verbal que se dá em uma canção? Isabelle Ost define este cruzamento de sentidos que se dá na imagem de um modo curioso: "a palavra diz o invisível que vê a vista e a vista vê o indizível que diz a palavra". ${ }^{39}$ Seria como sentir a aspereza de um som ou a leveza de uma visão. E este cruzamento só poderia se dar no campo das forças, campo sub ou intra-perceptivo, sendo da natureza daquilo que Deleuze chamará de intensivo,

\footnotetext{
38 Samuel Beckett, Poèmes, suivi de Mirlitonnades, Paris, Minuit, 1978, p. 26-27.

39 Isabelle Ost, Samuel Beckett et Gilles Deleuze : cartographie de deux parcours d'écriture, Bruxelles, Facultés Universitaires Saint-Louis, 2008, p. 275.
} 
ou o inextensivo de Henri Bergson.

Daí esta imagem ser quase imperceptível, invisível, inaudível - e de difícil demonstração. Ela é da ordem da irrupção, do efeito incorporal que se dá no corpo de quem lê, ${ }^{40}$ dando a ver e a ouvir coisas que extrapolam o escrito. Ela precisará acontecer em cada leitura, como se fosse disparada pelo fluxo que se dá entre as palavras ao serem acionadas quando lemos, no instante da performance do texto: instante em que o texto efetivamente se move e faz mover o corpo, músculos, respiração, de quem lê. Podemos dizer, portanto, que tal imagem dura o exato tempo da performance, afirmando no texto uma espécie de tempo real do próprio ato de leitura, e que, portanto, extrapola o tempo da representação, aquele fixado nas dimensões estritamente linguísticas do texto.

\section{Bibliografia}

ANDRADE, Fábio de Souza. Samuel Beckett: o silêncio possível. São Paulo: Ateliê, 2001.

BECKETT, Samuel. Cap au pire. Trad. Edith Fournier. Paris : Minuit, 1991 (do original Worstward Ho, 1983). Comment c'est. Paris: Minuit, 1961.

Como é. Trad. Ana Helena Souza. São Paulo: Iluminuras, 2003 (dos originais em francês Comment c'est, 1961, e em inglês How is it, 1964). . Companhia e outros textos. Trad. Ana Helena Souza. São Paulo: Globo, 2012. . Le Monde et le pantalon. Paris: Minuit, 1989. L'Image. Paris: Minuit, 1988. Mal vu mal dit. Paris: Minuit, 1981.

. Objet Beckett. Paris: Éditions du Centre Pompidou/ Imec, 2007.

. Oh les beaux jours - suivi de Pas moi. Paris: Minuit, 1963-1974.

Pra frente o pior. In: Companhia e outros textos. Trad. Ana Helena Souza. São Paulo: Globo, 2012. Poèmes, suivi de Mirlitonnades. Paris: Minuit, 1978.

Pour finir encore et autres foirades. Paris: Minuit, 1976, 1991, 2001, 2004.

Têtes-mortes. Paris: Minuit, 1967, 1972.

The Letters of Samuel Beckett v. II (1941-1956). Ed. George Craig, Martha Dow Fehsenfeld and Lois More Overbeck. Cambridge : Cambridge University Press, 2011.

Trois dialogues. Paris: Minuit, 1998.

BERNOLD, André. L'Amitié de Beckett. Paris: Hermann, 1992.

BlAnchot, Maurice. A parte do fogo. Trad. Ana Maria Scherer. Rio de Janeiro: Rocco, 1997 (do original La Part du feu, 1949).

CASANOVA, Pascale. Beckett, l'abstracteur. Paris : Seuil, 1997.

CLEMÉNT, Bruno. L'œuvre sans qualités - rhétorique de Samuel Beckett. Paris: Seuil, 1994.

DELEUZE, Gilles. . Cinema 2 -l'image-temps. Paris : Minuit, 1985.

\footnotetext{
40 Relaciona-se com esta formulação a concepção de sentido trabalhada por Deleuze ao longo de toda sua filosofia, especialmente a partir de Lógica do sentido, em que o sentido é tido como um acontecimento, um efeito incorporal que se desprende dos corpos; o sentido como "a fronteira entre as proposições e as coisas", sendo da natureza de uma força que atravessaria as dimensões linguísticas (e empíricas) do enunciado. Gilles Deleuze, Logique du sens, Paris, Minuit, 1969, p. 35. Ou ainda, como se lê em Ilha deserta e outros textos, mais em relação a nosso tema: "sentido como efeito produzido por uma certa maquinaria, como efeito físico, ótico, sonoro etc. (o que não quer dizer de modo algum uma aparência)". Gilles Deleuze, L'Île déserte et autres textes, Paris, Minuit, 2001 .
} 
$1 9 9 3 \longdiv { . }$

Crítica e clínica. Trad. Peter Pál Pelbart. São Paulo: Ed.34, 1997. (do original Critique et clinique, Francis Bacon: logique de la sensation. Paris : Seuil, 2002.

“L’Épuisé”. In: Beckett, Samuel. Quad et autres pièces pour la télévision. Paris : Minuit, 1992.

. Logique du sens. Paris: Minuit, 1969. e PARNET, Claire. L'Actuel et le virtuel. In: Dialogues. Paris: Champs, 1996, p.179-185.

DIDI-Huberman, Georges. Image. In: Objet Beckett. Paris: Éditions du Centre Pompidou/ Imec, 2007.

ESSLIN, Martin. Une poésie d'images mouvantes. In: Révue d'Esthétique : Samuel Beckett, 1986.

GIL, José. Fernando Pessoa ou a metafísica das sensações. Lisboa: Relógio D’Água, 1996.

GROSSMAn, Evelyne. La Défiguration-Artaud-Beckett-Michaux. Paris : Minuit, 2004.

HUBERT, Renée Riese. À la trace de Bing. In: Cahier de l'Herne, Samuel Beckett. Édition de 1 'Herne, 1976, p. 269-279.

KLEE, Paul. La Pensée créatrice. Paris: Dessain et Tolra, 1980.

OST, Isabelle. Samuel Beckett et Gilles Deleuze : cartographie de deux parcours d'écriture. Bruxelles : Facultés Universitaires Saint-Louis, 2008.

PERLOFF, Marjorie. The poetics of indeterminacy - Rimbaud to Cage. Evanston: Northwestern University Press, 1999. 